\title{
CONSERVATION OF RESOURCES: A PRIMARY INTERVENTION FOR CONTINUOUS TRAUMATIC STRESS IN SOUTH AFRICA: A CASE STUDY
}

\section{M van der Merwe, K Kassan-Newton}

\section{INTRODUCTION}

Many mainstream conceptual models guiding post-trauma intervention have been developed, and are utilised in accordance with theoretical and professional orientation. In many of these models the response to trauma has come to be postulated as an internal phenomenon. Conceptually, the stress response has been separated from its original source in the external environment, and has been located in the individual (Hobfoll, 1998; Monnier \& Hobfoll, 2000). Medical or pathologybased responses to trauma often highlight deficiencies in the traumatised individual, who is treated by the "expert" psychiatrist or psychologist, based on the needs the specialist identifies. In South Africa, an exception is the social work profession, where a developmental approach has been applied to South African policy and intervention since 1997 when the White Paper for Social Welfare was formulated (Ministry for Welfare and Population Development, 1997).

This critique of mainstream psychology (Gulerce, 2001) has been voiced many times in critical psychology literature. In this paper we would like to support this critique without denigrating the dedication and commitment that has gone into developing mainstream approaches in psychology.

Considering the realities of the people to whom, as health care professionals, we are accountable, alternative ways of practice must be considered. These alternative approaches can become primary, complementary or addended to traditional approaches. They are intended to serve the large numbers of people disempowered in various ways in developing countries, who may not benefit from mainstream approaches as they are currently practiced. One of the realities in South Africa is that people and communities are immersed in continuous traumatic stress, implying that the term post-traumatic stress falls short when applied in this context.

Psychiatrists, psychologists and social workers that work in developing countries, and utilise strictly traditional models in their practice are in danger of being inundated by the sheer volume of services required by clients (Ebersöhn \& Eloff, 2003). This is especially evident in South Africa, where psychiatrists, psychologists and social workers employed in public health care services face endless lists of client problems and deficiencies, for which the resources to deliver acceptable services are lacking, and in some cases, non-existent. Against the backdrop of serious social problems and challenges to development, traditional models of intervention and service delivery are inadequate. Professionals, who are often driven by the intrinsic need to help people, frequently become demotivated and risk burnout. In South Africa this may be reflected in the droves of professionals having left and continuing to leave the country for greener pastures elsewhere. In this context the Conservation of Resources (COR) theory is presented as a framework for practice, extending beyond traditional biological and psychological conceptualisations, and taking into account broader social, cultural and contextual factors.

In this paper, the authors utilize a descriptive and exploratory approach to present COR theory within the South African context, by using a case study. In order to deliberate on the application of COR to South Africa, a brief overview follows of South African conditions.

\section{A SOUTH AFRICAN PROFILE}

In an article in the newspaper Rapport, Buys (2004) refers to Terreblanche's classification of the South African population in three groups of more or less 15 million each. The first group consists 
of about four million white people and 11 million black people who receive about $88 \%$ of the country's income. The second group of 15 million people consists mainly of black people, who receive about $8 \%$ of national income. The last group of 15 million obtains only $4 \%$ of national income and consists mainly of black people. Unemployment affects $43 \%$ of the population. Buys further states that almost half of the South African population lives in conditions of extreme poverty, and that about six million people receive some form of welfare grant. A core characteristic of South Africa is its dual economy, with a well-developed modern sector versus a poor informal sector (Gathiram, 2005), where informal work offers meagre resources for those who do not have access to formal employment. Many of those in the informal sector have limited school education and consequently may be functionally illiterate. On the other hand, highly educated people from other parts of Africa are found in the informal system when they cannot find skills-related jobs in the formal sector.

Although South Africa has shown incredible resilience and growth since the advent of democracy, it is well known that violence and psychosocial trauma prevail. Already ten years ago Hamber and Lewis (1997:1) stated that South Africans are said to live in a "culture of violence" in which violence and aggression are sanctioned as a means of resolving problems and achieving goals, an opinion which still rings true today. The years of sometimes insidious violence perpetrated under apartheid has “... undermined the moral, interpersonal and social fabric of South African society" (Hamber \& Lewis, 1997:5) and may have served to disguise as political other types of violence that have emerged so forcefully today (Hamber, 1999).

Many communities in South Africa are steeped in chronic, ongoing violence, including domestic violence and family murders. Criminal victimization is rife, and gangsterism is well established as a means of obtaining resources. Other typical South African incidents with damaging potential are car hi-jackings, cash-in-transit heists, and sexual trauma including rape, gang rape and sexual molestation of children. The scourge of HIV/AIDS, which directly affects about six million people in South Africa, impacts directly on the economic situation of the country by depleting valuable resources (Van Dyk, 2001).

Social inequality and deprivation caused by the apartheid system (Gathiram, 2005) are recognized as a root cause of violent crime in South Africa (Hamber, 1998; Palmary, 2001). Poor people bear the brunt of violence in society and have little chance of escaping it. Their children are born into these circumstances, often knowing no other reality, and aggression quickly becomes a way of life. However, this does not mean that high levels of poverty always result in increased levels of violence and crime in communities, but the stress of poverty brings with it severe implications that are intrinsically linked to violence, such as over-crowding, family disruption, high concentrations of people living together and population transience (Hamber, 1999).

Segments of South African society show signs of being a corrosive community, and the corrosiveness refers to the impact of South Africa's history. When the Nationalist government implemented its policy of racial segregation, well established communities were uprooted and relocated against their will, and became increasingly economically disadvantaged (McKendrick, 1990; SA Yearbook, 1995). Fourteen years after the advent of democracy, many South Africans still feel deprived, and whole communities continue to suffer. The corrosiveness in this country is manifested in concerns about crime and safety across all groups and in all areas. South Africans have little faith in the criminal justice system, and when the system has failed them, some of them have, in frustration, taken the administration of justice into their own hands. 
It is clear from this profile that there are specific challenges in the South African situation which might render more traditional approaches to trauma ineffectual. As mentioned previously, certain concepts such as post-trauma may be challenged in the South African context where continuous trauma typifies the lives of many people. COR theory is examined here as an alternative approach in a society where multiple traumatic occurrences are common and, where continuous traumatic stress prevails.

\section{CONSERVATION OF RESOURCES THEORY}

In order to understand Conservation of Resources theory, it is necessary to appreciate the concepts employed, the premises underlying the theory, and the principles that guide its application, which are discussed briefly below.

The inclusion of resources in crisis theory has historical roots in the work of Caplan (1964) as cited by Ewing (1978:13) who stated that: “... the essential factor determining the occurrence of crisis is an imbalance between the perceived difficulty and significance of the threatening situation, and the resources available immediately for coping with the situation." According to Hobfoll, Dunahoo and Monnier (1995:516), resources are defined as “...those objects, personal characteristics, conditions, or energies that are valued by the individual or that serve as a means for attainment of these objects, personal characteristics, conditions, or energies". To illustrate, food is easily recognized as a resource, but employment to be able to earn money to buy food is not similarly acclaimed. More abstractly, personal esteem is a well-known resource that is commonly viewed as a form of human capital. However, contributing factors to self-esteem, such as a nurturing home environment, are also resources. In COR theory, four kinds of resources are described (Monnier \& Hobfoll, 2000), as in Figure 1 below.

\section{FIGURE 1 \\ RESOURCE CATEGORIES}

\begin{tabular}{|c|c|}
\hline Resource category & Examples \\
\hline $\begin{array}{l}\text { Object (functional } \\
\text { or status) }\end{array}$ & $\begin{array}{ll}\text { Individual: } & \text { Home, car, clothing, household items } \\
\text { Community: } & \text { Roads, industry, bridges and other forms of infrastructure }\end{array}$ \\
\hline Conditions & $\begin{array}{l}\text { Individual: } \begin{array}{l}\text { Social structures/roles, circumstances, good health, good } \\
\text { relationships, membership in organizations, reciprocity, mutual } \\
\text { trust, civic connections }\end{array} \\
\text { Community: Availability of employment, level of emergency services }\end{array}$ \\
\hline $\begin{array}{l}\text { Personal } \\
\text { characteristics/ } \\
\text { group or } \\
\text { community } \\
\text { attributes }\end{array}$ & $\begin{array}{l}\text { Individual: } \begin{array}{l}\text { Personal traits (self esteem, resilience, skills, sense of mastery, } \\
\text { work strategies, sense of optimism, independence), communal } \\
\text { pride, psychological sense of community, knowing how to act in } \\
\text { crisis, occupational skills }\end{array} \\
\text { Community: Community cohesion, community pride }\end{array}$ \\
\hline Energies & $\begin{array}{l}\text { Individual: Money, food, credit, insurance, heating, government financing, time } \\
\text { Community: Money, food, credit, heating }\end{array}$ \\
\hline
\end{tabular}

The resource categories of Hobfoll have overlapping features with social capital where aspects such as building networks and relationships, trust and attachment, resonates with condition and personal resources as described in COR theory. Social capital includes condition resources such as connections between people, mutual understanding, social networks, ubuntu and norms of reciprocity. Physical capital can be linked to physical objects and energy resources. Personal resources can be linked with human capital, which also refers to properties of individuals such as 
internal locus of control and a sense of coherence (Putnam, 2000:19). Building social capital will imply movement into gain spirals, whereas loss of social capital will entail downward movement into loss spirals. Social support has frequently been described as a crucial buffering factor in the wake of trauma, but as stated by Schumm, Hobfoll and Keogh (2004:174): “... erosion of social resources often follows traumatic events and subsequently exacerbates psychological distress." Revictimisation and exposure to continuous stress typically lead to general interpersonal resource loss, and constant pressure on other resource domains.

\section{FIGURE 2 \\ COR-EVALUATION}

\begin{tabular}{|c|c|}
\hline Personal transportation & Ability to organise tasks \\
\hline Feeling that I am successful & Extras for children \\
\hline Time for adequate sleep & Sense of commitment \\
\hline Good marriage & Intimacy with at least one friend \\
\hline Adequate clothing & Money for extras \\
\hline Feeling valuable to others & Self-discipline \\
\hline Family stability & Understanding from employer/boss \\
\hline Free time & Savings or emergency money \\
\hline Clothing that is more than I need & Motivation to get things done \\
\hline Sense of pride in myself & Spouse/partners health \\
\hline Intimacy with one or more family members & Support from co-workers \\
\hline Time for work & Adequate income \\
\hline Feeling that I am accomplishing my goals & Feeling that I know who I am \\
\hline A good relationship with my children & Advancement in education/training \\
\hline Time with loved ones & Adequate credit (financial) \\
\hline Necessary tools for work & Feeling independent \\
\hline Hope & Companionship \\
\hline Children's health & Financial assets (stocks, property etc.) \\
\hline Stamina/endurance & Knowing where I am going with my life \\
\hline Necessary appliances for home & Affection form others \\
\hline Feeling my future success depends on me & Financial stability \\
\hline A positively challenging routine & Feeling that my life has meaning/purpose \\
\hline Personal health & Positive feelings about myself \\
\hline Housing that suits my needs & People I can learn from \\
\hline Sense of optimism & Money for transportation \\
\hline Status/seniority at work & Help with tasks at work \\
\hline Adequate food & Medical insurance \\
\hline Home that is more than what I need & Involvement with church, synagogue etc.. \\
\hline Sense of humour & Retirement security (financial) \\
\hline Stable employment & Help with tasks at home \\
\hline Intimacy with spouse/partner & Loyalty of friends \\
\hline Adequate furnishings for home & Money for advancement or \\
\hline Feeling that I have control over my life & (education, starting business) \\
\hline A role as leader & Help with childcare \\
\hline Ability to communicate well & Involvement in organisations with others who have \\
\hline Essentials for children & similar interests \\
\hline Feeling that my life is peaceful & Financial help if needed \\
\hline Acknowledgement for accomplishments & Health of family/close friends \\
\hline
\end{tabular}


Hobfoll (1998) suggests that the range of resources is delimited according to what is universally valued. However, he notes the argument that this concept is potentially unwieldy because of its broad range, as anything that is of any value at all could be regarded as a resource. To narrow the focus, Hobfoll conducted a series of group discussions, in which he asked members from different social and cultural groups to nominate valued resources. The results showed strong agreement across the groups, and even across cultures. The preliminary 74 items that emerged formed the basis of the evaluation of resources which Hobfoll et al. (1995:33) incorporated into a tool named Conservation of Resources - Evaluation (COR-E) (see Figure 2 below). For South African society the 74-item list below will most likely not be conclusive and will require further research.

According to COR theory, psychological stress occurs when there is the threat of significant resource loss; actual resource loss or failure to gain resources after investing resources, i.e. when more was lost in the process of investment than gained as outcome of investment (Hobfoll \& Lilly, 1993). People strive to protect, obtain and retain what they value. Acute stressful conditions such as disasters place communities in a vulnerable position, as they result in rapid resource loss. Chronic stressful conditions chisel away even strong resource reservoirs. Those who are already poor, disenfranchised and discriminated against are more vulnerable to the loss of resources due to continuous traumatic stress.

The concept of loss is significant in COR theory. The theory predicts that individuals act to try and minimize net resource loss when they are at risk of resource loss. When not confronted with stress, individuals build up resource surpluses in order to minimize the impact of future losses. COR theory posits a number of key principles, namely the primacy of loss (loss is more heavily weighted than gain); investment of resources (to obtain, retain and protect resources); and vulnerability to further loss (initial losses render persons/communities more vulnerable to further loss).

The key principles of COR theory shed light on responses to traumatic stress. In terms of the first principle, namely the primacy of loss, when individuals encounter traumatic stress, psychological distress occurs. Any gains that may occur have little effect in terms of reducing psychological distress, and are valued to the extent that they counteract the loss. For instance, a child's improvement in health after a long illness is seen as significant, whereas hearing that your child is in good health in the absence of illness will have little effect on one's state of mind (Hobfoll et al., 1995). However, these authors caution that significant losses occurring simultaneously may result in more extreme effects than may be anticipated, and that neither the effects of losses nor gains should be under or overestimated.

In terms of the second principle, the investment of resources to obtain, retain and protect resources, individuals may invest in enriching existing assets, thereby conserving resources over the long term. Individuals offset the loss of, or acquire resources, by harnessing the resources they already have. Resource investment could occur in its most obvious forms, as in money, insurance or time, but also in other forms such as deciding to trust someone, taking a risk to disagree with a senior colleague, or substituting lost love by immersing oneself in one's career (Hobfoll, 1998). Stress occurs when there is threat or loss of resources, requiring one to invest resources to prevent or offset further losses, and also to make gains. For instance, after having been raped, a woman may lack self-esteem and confidence, and may be afraid to go outside. By joining a rape survivors group she will invest in building her confidence again, and develop an identity as a survivor. This principle of COR contradicts theories that predict helplessness in the face of trauma. Instead, it suggests that trauma motivates coping behaviour (Hobfoll et al., 1995). 
Freedy, Shaw, Jarrell and Masters (1992), for instance, found that in responding to stress, victims actively initiate coping behaviours available to them, regardless of whether they have beneficial or detrimental outcomes.

The third COR principle postulates that initial losses render persons/communities more vulnerable to further loss. The dynamic of loss and gain spirals refers to the individual's vulnerability to further losses after an initial loss has been endured. Following an initial loss, the person's most potent resources are used to counteract further challenges that inevitably occur. Thereafter, more resources are invested, which could be depleted to cope with subsequent challenges. This process could repeat itself, and could very quickly descend into a loss spiral, which could continue to affect individuals long after the stressful incidents have occurred. Various research findings have provided further information on resource loss cycles. McFarlane (1993) and Ruch and Leon (1986, cited in Hobfoll et al., 1995) found in separate studies that once the resource threshold has been overloaded, loss cycles accelerate as the impact and psychological effects increase. Similarly, a study by Kaniasty and Norris (1993, cited in Hobfoll et al., 1995) found that chronic stress depletes resources both because stress results in resource loss, and because repeated investment and loss of resources eventually leads to partial or full depletion of resource reserves.

As with loss spirals, gain spirals require resources to be invested. Gains take place soon after the critical event, and build resilience and create capacity to accommodate further gains. With reference to the earlier example of the woman who was raped, by investing time and energy to join a rape survivors' group she sets in motion a gain spiral in that she processes her experience, feels better about herself, acquires social support, and learns skills for better coping.

Hobfoll (1998) and Monnier and Hobfoll (2000) have noted important outcomes of these principles that must be borne in mind when planning interventions. These principles are significant when intervening in the context of continuous trauma, which is the challenge to South Africa and many developing countries. The majority of people in these contexts are caught up in resource-poor situations before exposure to traumatic events, while immersed in situations of ongoing trauma. Based on his work, Hobfoll (1998) has developed several principles for intervention, as outlined in the section below and illustrated in a case study.

\section{PRINCIPLES OF INTERVENTION}

Within the context of continuous traumatic stress in South Africa, Conservation of Resources theory offers a transdisciplinary, overarching approach. COR then becomes the framework for intervention, into which helping efforts from mainstream approaches can be incorporated as resources. Therapeutic intervention will then be a condition resource that leads to gain in other categories. Referring back to the example of the rape victim, by having the condition resource of the rape survivors' group available, she will make gains in personal resources such as renewed confidence and survivor status. Hobfoll (1998:246) does not suggest that COR must be applied to the exclusion of other approaches, and indeed he states, “...even in areas where psychopathology must be attended to by traditional methods, COR theory offers suggestions for intervention that would addend traditional treatment and improve quality of life". Hobfoll (1998:246-260) offers the following principles for intervention on individual, group or broader systems levels.

First, act to prevent or limit loss. Loss cycles are more rapid in momentum, and more intense in magnitude than are gain cycles. This means that intervention efforts need to move more quickly to offset loss cycles than to introduce gain cycles. This is particularly critical when working with resource-poor individuals or systems, because losses may produce such severe damage that the 
resources required to halt the loss cycle may be outside the means of the individual, group or community.

Second, begin initiation of gain-focused interventions. One does not have to wait until loss cycles are completely halted in order to successfully begin gain processes. The downward cycles have to be sufficiently limited to enable the affected entities to invest their limited existing resources to reverse the loss spiral. Because resource gain is secondary to loss, the second step of the intervention should aim to create new resources and smooth their implementation. Gain cycles take longer to gather momentum and to develop. Individualised, gain-focused interventions can be designed more slowly and systematically.

Intervention must consider the resource strengths and weaknesses of the target unit. Traditional approaches mostly focus their treatment on specific pathologies (e.g. depression, anxiety), which present just one portion of a complex picture. When a client does not come to therapy, their lack of participation is often attributed to resistance, or lack of motivation. In resource-poor entities, non-participation could be due to their having insufficient resources to engage in the intervention, e.g. transportation, self-esteem, social support, time and energy. COR offers the view that successful intervention requires that a full picture of the entity's resources be obtained, so that factors that make participation possible can be addressed, assisting the entity to call upon or invest in existing resources, thereby increasing sense of ownership in recovery. Where this is not done, it is likely that resource-depleted entities will be more likely to adopt a defensive posture, so as to protect whatever resources they have.

Target resources, not illness. The intervention should not just target the symptom or illness, but should include the resources and conditions that contribute to optimal functioning. Such a strategy will both address traditional mental health outcomes, while enriching resource reserves, which can be used to offset future threats and augment gain cycles.

Focus on key resources. Certain resources will be central in resource gain and loss spirals, depending on the norms that accompany person-environment interactions in a specific culture or setting. For instance, in a community stricken with gang violence, taking a child to see the results of a gang shootout may be ill-advised according to literature on traumatic stress and children, but in some resource-poor communities such behaviour may be one in a small armamentarium of resources, as it may be instrumental in turning children away from a life of gangsterism. This principle requires that the interventionist develop an appreciation for the different ways of life in many societies, so as to identify key resources.

Target multiple resources. When individuals confront extreme stress, they are affected across more than one domain, and require intervention on multiple levels to counteract negative outcomes. Bandura (1994, cited in Hobfoll, 1998) provides the example of women who had been raped being taught an aggressive means of self-defence as a key resource, and also other techniques such as verbal persuasion, appearing confident and decision making under attack. A single resource could be easily overwhelmed, while multiple resources allow for a multiple defensive strategy.

Adaptation and change have definite and sometimes overwhelming costs. Because coping, adaptation, and attempting resource gain requires resources to be expended, these processes will tend to deplete resources. Interventionists must anticipate this occurrence, and plan for these costs by building in circumventive strategies.

Look to alter systems-individual resource fit. Sometimes individuals with limited power or those experiencing discrimination may be prohibited from accessing existing resources, or from 
investing resources, requiring that intervention be aimed at altering social systems, not individuals or groups.

Watch for spin-off effects. Interventionists must vigilantly monitor the effects of intervention strategies and watch for expected and unexpected consequences, and to take this information into consideration as the intervention unfolds.

Traumatic resource loss leads to lifelong vulnerability and vigilance. Individuals who experience resource loss develop resource loss sensitivity, and an attitude of vigilance to loss. This response may be exaggerated in those who experience resource loss in early childhood, because they will have had to protect against losses when they were ill-equipped, or before they were mature enough to do so.

Attempts to alter appraisals must be consistent with social norms. These attempts will be more effective if they dovetail initial attempts to optimise resources-demand fit and compensate for lacking resources. Hobfoll (1998:256) stresses that “...this principle deserves special attention because it is both a complex axiom and it is fundamental to change". It deals with incorporating the role of cognitive appraisals as part of a resource-based approach. According to this principle, people will resist making cognitive appraisals that appear to be contraindicated by reality. This principle is clearly demonstrated when working with resource-poor individuals who may be so focused on bread-and-butter issues that many forms of intervention are contraindicated until these issues have been addressed. Additionally, if a computer programmer is paralysed in an accident, and she is able to continue doing her job after accommodations at work, she may adapt better to her situation. This process is called "accommodative coping" (Hobfoll, 1998:258) and could lead to adjustment of past goals and aspirations.

It should be noted that Hobfoll's approach has all along been systemic, in that he sees the individual unit as being indivisible from the rest of the system. Intervention on the individual level will reverberate throughout the other levels, and could have expected as well as unintended consequences.

In this section principles of intervention spanning individuals, groups and communities, were discussed. In the following section COR theory and principles of intervention will be applied in a case study.

\section{CASE STUDY}

The main feature of this case study is the impact of an extreme event, namely, a hit-and-run pedestrian accident which resulted in severe injuries. However, the subject of the case study was already functioning with limited resources.

Mr. L has a history of childhood sexual trauma, which he only disclosed as an adult during counselling at his place of work where the presenting problem was substance abuse. He joined a gang when he was 12 years old. To move through the hierarchy of the gang, he was involved in criminal activities. Initially this entailed stealing and housebreaking, which progressed to rape and murder. He mentioned that he witnessed the rape but actually committed two murders by shooting. He did not want to disclose much regarding these killings, as he feared criminal prosecution. He was troubled by intrusive imagery regarding the witnessed rape, and the two murders. He felt intense guilt about his participation in these activities. When he was 18 years old, a friend was shot dead next to him during a gang-related shooting. At age 20, when he tried to lead a life away from the gangs, he was abducted by an opposing gang who suspected him of killing one of their gang members. He was held at gunpoint and was assaulted and released after 
two days. All these issues were still mainly unresolved when he was the victim of a hit-and-run pedestrian accident at age 25, while under the influence of various substances. He sustained serious head and leg injuries, and was hospitalised for six months. In the aftermath of the accident Mr. L's functioning fluctuated between periods of relative stability to periods where substance abuse increased, relationships deteriorated and he experienced depression and suicidal ideation. He admitted to using substances as an excellent but counterproductive form of avoidance. Another form of avoidant behaviour was excessive television watching, as in watching "poppentjies" (cartoons) with small children from the community. He also avoided the location of the accident.

A number of resources fed into a gain spiral for Mr. L. At the time of the accident, he was stably employed, and had the security of a provident fund and access to sick leave payments. Even before the accident, he had developed a trusting relationship with the social worker at the workplace, to whom he had reached out when he felt that his "backyard was dirty" (a metaphor used when he was pre-occupied with thoughts and images of the traumatic incidents described above). While in hospital, managerial and non-managerial co-workers regularly visited $\mathrm{Mr}$. L, and brought gifts as encouragement. Another significant resource was a strong family system, with an especially supportive mother and brother. After the accident Mr. L's employer retained his services, and the social worker also referred him to a weekend retreat for memory work to promote trauma integration. Mr. L also received monetary compensation from the Road Safety Fund.

\section{POST-TRAUMA INTERVENTION FROM A CONSERVATION OF RESOURCES PERSPECTIVE}

In this article, a framework for intervention is proposed in the context of Conservation of Resources theory. Many conceptual models have been developed to guide intervention in the wake of trauma. These models show similarities and as Herman (2001:155) states: “...a rough congruence" is to be found in the processes and phases.

Draucker and Martsolf (2006:27) are of the opinion that phase-oriented interventions are wellaccepted when working with trauma victims, stating that: "There is much consensus in the literature regarding the stages, nature, and goals of treatment. Several authors describe an early phase of treatment that focuses on stabilization and mastery, including building the therapeutic relationship, attenuation and containment of stress-related symptomatology, establishing safety, and coping with current life problems. The second phase typically involves the integration of traumatic memories. A final phase often focuses on self-development, relational development, or adaptation to daily life."

The question can be asked what COR theory can add to these well-established models. COR theory keeps in focus aspects that might be overlooked in more traditional approaches such as accentuating resources that do not immediately seem to be resources from a conventional framework. COR theory also emphasises primacy of the client's perspective and not that of the professional helper's as well as the use of language that is meaningful to the client system. COR encourages a holistic and ecosystemic perspective, in which loss and gain spirals constitute an overriding construct within which all assessment outcomes can be integrated and intervention evaluated. As with other approaches, a key function is compiling individualised intervention strategies for affected entities.

While the framework for intervention proposed in this article is tentative, already a certain sequence in terms of order of work is evolving. In this regard it seems apt to examine, in the 
initial phase, aspects such as the impact of mediating variables and an evaluation of resources (COR-E), which could be attended to simultaneously or consecutively. Additional tasks might be included, such as expanded psycho-education to incorporate resource categories, information about loss and gain spirals, looking at client strengths and constructive coping. An important consideration when working within this framework is that of the roles that helpers take, which could be broader than those traditionally adopted.

\section{PROFESSIONAL ROLES}

Professional helpers hold various roles during intervention with traumatised populations. Importantly, interventionists are facilitators or midwives on the way to transformation of traumatic stress. Ownership for each process should always be with the target individual, group or community. Other crucial professional roles are those of mediator, educator and advocate. Important skills are those of networking with relevant resources, and sustaining links between resources and target populations. A crucial role is that of collaborator, helping clients to rescript and reframe their trauma narratives where the interventionist acts as coach, with a focus on clients' strengths. For instance, some symptoms such as moderate hypervigilance could be reframed as adaptive to keep the client safe (Hoyt, 2000; Pearlman, 2001). Interventionists also function as auxiliary egos to support the limited ego strength of traumatised people when working directly with their experiences or identifying and accessing resources. Maybe there is a new role for service providers in the context of continuous trauma, that of "asset detective". This would entail identifying, together with the affected entity, resources in their environment, which would support them successfully addressing their needs. A guiding principle for helping professionals should be that the client is empowered during the helping process, so as not to reproduce the powerlessness inherent in trauma exposure. These professional roles can be applied as described below.

\section{MEDIATING VARIABLES}

An important task when working from a COR perspective is for interventionists to assess mediating variables, which could have both protective and risk functions. A thorough assessment of those variables that mediate the unique response of each traumatised entity is indicated. These variables offer the key to understanding the effects on units, and also tools for formulating practical, concrete and workable intervention strategies. James (1989:49) likened mediating variables to: "...the myriad pieces of coloured glass in a kaleidoscope; the basic pieces are the same, but a different pattern appears every time the kaleidoscope is moved". This implies that each affected entity will have different intervention needs. The groups of variables in Figure 3 below can be referred to (Van der Merwe, 1999:84) when assessing mediating variables.

With reference to the case study, a significant mediating variable in terms of risk could be Mr. L's trauma history, as represented in Figure 4 below, using a timeline (a useful technique when assessing trauma history). This timeline shows that Mr. L experienced severe levels of continuous trauma over many years which are likely to have had a profound effect on current functioning. In Mr. L's case, the moderate and manageable level of current stress had a buffering effect, in that it provided respite and allowed him to build resources. 
FIGURE 3

MEDIATING VARIABLES

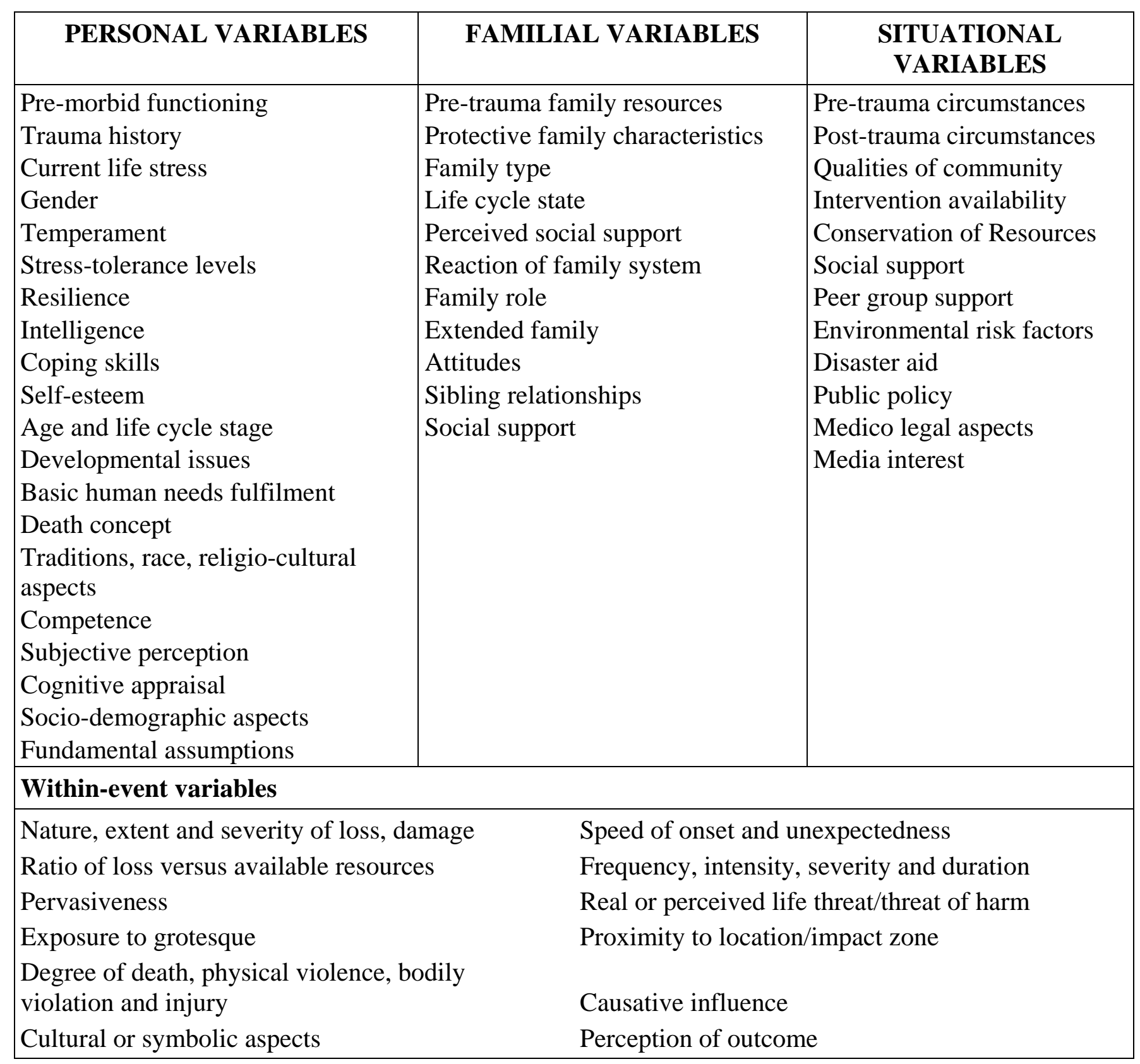

In most cases of trauma, client trauma history and assessment of current life stress are likely to be assessed, due to their general relevance in terms of the impact on the entity as well as coping mechanisms. To recap, assessment of moderating variables provides information on the unique compilation of factors mediating each individual entity's response. Conservation of ResourcesEvaluation (COR-E), as discussed below, indicates those resources valued by each entity. 
FIGURE 4

TRAUMA HISTORY OF MR. L
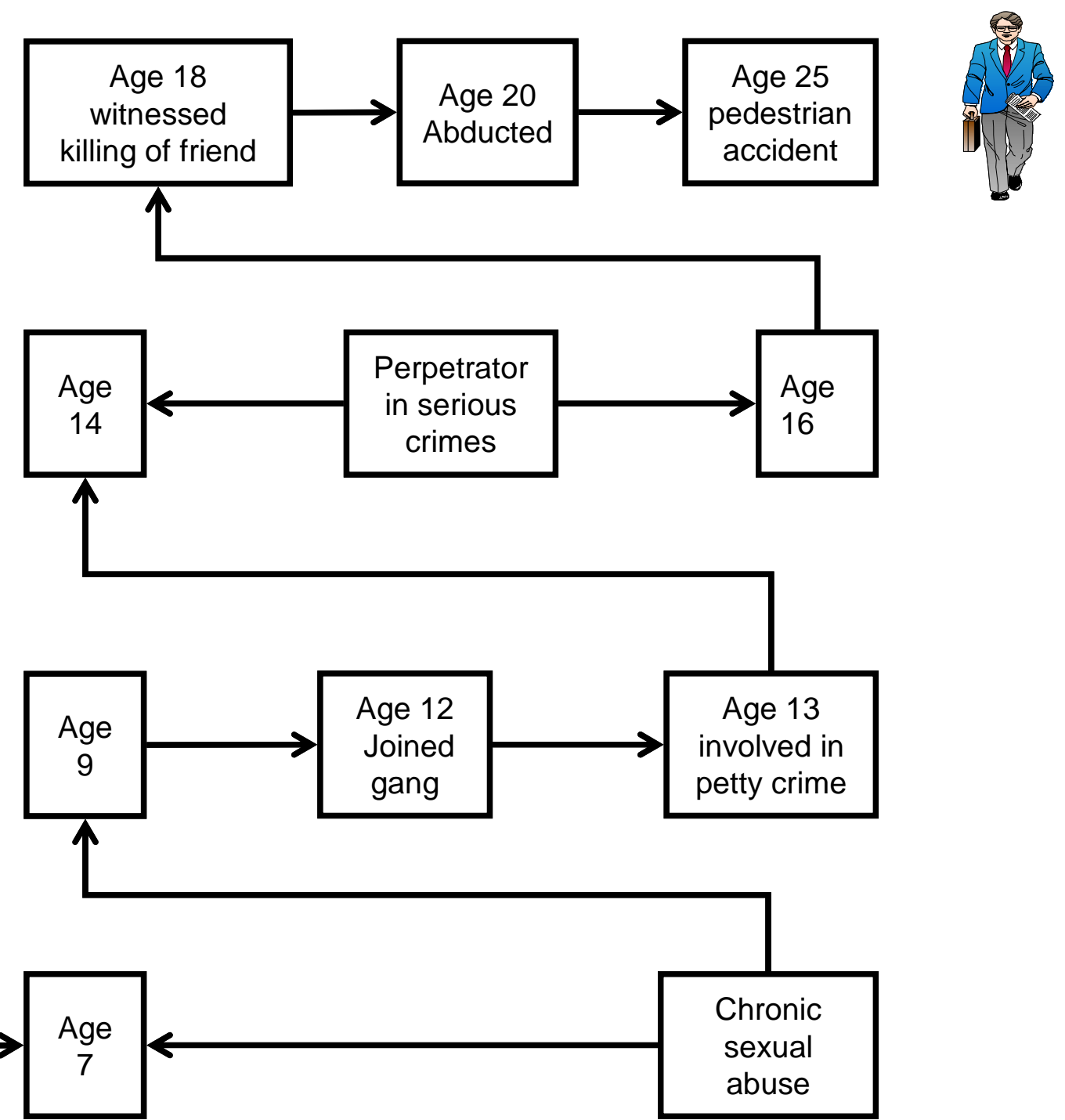

\section{LIFELINE/TIMELINE}

\section{CONSERVATION OF RESOURCES-EVALUATION (COR-E)}

COR-E is also an early intervention task (as is the assessment of mediating variables). COR-E entails a thorough assessment with affected entities to consider the resources they value. This involves assessing the interplay of resources in pre-trauma, impact and post-trauma phases, from within the subjective impression of each affected entity. To assess valued resources, the list in Figure 2 above could be utilised, and refined or adapted for each traumatised unit. Once valued resources have been identified, they can be prioritised, and strategies devised to set in motion gain spirals. Continued employment was one of Mr. L's most valued resources. This prevented financial hardship, which could have led to further loss. The gains of continued employment were enhanced self esteem and continued support from fellow workers.

\section{Assessing loss and gain spirals}

After identification of valued resources, it is useful to diagrammatically represent both loss and gain spirals. COR theory indicates that the momentum of loss spirals is more rapid than gain spirals, suggesting that immediate effort should be directed at halting or slowing downward 
momentum (Hobfoll, 1989). Because loss is more potent than gain, and frequently has serious consequences, gain cycles occur more slowly and have less impact than do loss cycles. Hobfoll and Lilly (1993) alluded to the rapid momentum of resource loss cycles and how difficult it becomes to generate adequate resources to halt them. Not intending to be all-inclusive, Figures 5 and 6 below illustrate aspects of loss and gain spirals related to the case study.

\section{FIGURE 5 \\ LOSS SPIRAL}

Object: After the accident, Mr. L could not care for himself physically.
Neglected personal hygiene led to others avoiding him. Access to public
transport was restricted due to injuries
Condition: Loss of health, drop in production targets at work, trauma-
related reactions i.e. dissociation and suicidal ideation; impairment of
functioning of legs and arms, affecting ability to run and move fast (this
is a concern for him linked with hypervigilance - how will he be able to
get away from danger?)
Personal: Self-esteem, sense of security, sense of personal
invulnerability, loss of trust, attachment problems, loss of freedom of
movement
Energy: Loss of income, material deprivation due to substance abuse

Feeding into the gain spiral in this case study are the following resources to counteract the negative downward trend.

\section{FIGURE 6 \\ GAIN SPIRAL}

Object: Obtained own wooden structure to live in parents' backyard. No change in employment situation

Condition: Quickly recovered ability to live independently; income not affected; safety net of unemployment payments and temporary disability grant; support from church community

Personal: Enhanced self-esteem (contrary to initial negative predictions he succeeded in going back to work in the open labour market); self-efficacy (the knowledge of having been able to overcome trauma-related challenges again); a retained sense of autonomy and belonging (to family and labour union); strong religious beliefs

Energy: Income, money for extras, provident fund, access to health clinic and social welfare service

The process of loss and gain spiral assessment is dynamic, and ideally should continue all through the helping process. Thereafter, strategies should be formulated to incorporate valued resources, in order to facilitate movement into gain spirals.

When formulating an individualised intervention strategy based on loss and gain spiral dynamics, both tangible and intangible resources should be taken into account. Intangible resources include personal and condition resources such as strengths and nurturing relationships, while tangible 
resources include energy and object resources such as food and shelter. The role proposed above of "asset detective" could be applied here.

The "asset detective" could utilise non-traditional tools such as walking through the community with the client to identify resources. Based on practical information relevant to the client's situation, asset and risk maps can be compiled. An asset map is a client-friendly, pictorial representation of the assets and risks that exist in a client's world in terms of physical structure, and could be extended to psychological space. For instance, maps of the area in which the client lives showing community centres, schools, hotspots for violence, etc could be used creatively when planning the strategy for intervention. The design of asset and risk maps could offer space for creativity, as in using similar colours to denote comparable categories of assets and risks.

The expansion of this framework exceeds the scope of this article, which is meant as an introduction. The framework gives an indication of what is meant by the combination of COR with more traditional models. This approach begins with the assessment of mediating variables, followed by a thorough COR-Evaluation, and a graphic depiction of loss and gain spirals. Through this process an intervention plan is developed in which the COR is the primary modality, and in which the more traditional modes are incorporated as appropriate resources.

\section{CONCLUSION}

Kistner (2004) rightly states that mental health professionals in South Africa must develop practical intervention strategies based on their understanding of survival under conditions of continuous traumatic stress. Conservation of Resources offers a psychosocial approach to people exposed to continuous, repetitive trauma. More ways must be explored to replenish resources creatively and appropriately for each affected entity. This article will hopefully form a theoretical basis for future research into the unique challenges of working in the context of multiple, ongoing traumatic stress. Fundamentally, interventionists require a solid understanding of COR to apply this way of working.

We are hopeful that this article will stimulate debate and research in the fields of COR and trauma, and provide productive ways forward in developing countries with their unique challenges of continuous trauma and multiple stressors often linked to limited resources.

\section{REFERENCES}

BUYS, F. 2004. Suid-Afrika sal nuut moet dink én doen. Rapport, 18 Julie: 20.

DRAUCKER, C.B. \& MARTSOLF, D.S. 2006. Counselling survivors of childhood sexual abuse $\left(3^{\text {rd }}\right.$ ed). London: Sage Publications.

EBERSÖHN, L. \& ELOFF, I. 2003. Life skills and assets. Pretoria: Van Schaik Publishers.

EWING, C.P. 1978. Crisis intervention as psychotherapy. New York: Oxford University Press.

FREEDY, J.R., SHAW, D.L., JARRELL, M.P. \& MASTERS, C.R. 1992. Towards an understanding of the psychological impact of natural disasters: An application of the Conservation of Resources Stress model. Journal of Traumatic Stress, 5(3):441-454.

GATHIRAM, N. 2005. Poverty alleviation: The need for a knowledgeable, active and empowered civil society. Social Work/Maatskaplike Werk, 41(2)123-130.

GULERCE, A. 2001. Towards a critically critical psychology. International Journal of Critical Psychology, Launch issue: 121-124. 
HAMBER, B. \& LEWIS, S. 1997. An overview of consequences of violence and trauma in South Africa. Research paper. Centre for the Study of Violence and Reconciliation.

HAMBER, B. 1998. Dr Jekyll and Mr Hyde: Violence and transition in South Africa. In: BORNMAN, E., VAN EEDEN, R. \& WENTZEL, M. (eds), Violence in South Africa. Pretoria: Human Sciences Research Council.

HAMBER, B. 1999. Have no doubt it is fear in the land. An exploration of the continuing cycles of violence in South Africa. Zeitschrift für Politische Psychologie, 7(1/2):113-128.

HERMAN, J.L. 2001. Trauma and recovery: From domestic abuse to political terror. USA: Basic Books.

HOBFOLL, S.E. \& LILLY, R.S. 1993. Resource Conservation as strategy for community psychology. Journal of Community Psychology, 21:128-148.

HOBFOLL, S.E., DUNAHOO, C.A. \& MONNIER, J. 1995. Conservation of resources and traumatic stress. In: FREEDY, J.R. \& HOBFOLL, S.E. (eds) Traumatic stress: From theory to practice. New York: Plenum Press: 29-47.

HOBFOLL, S.E. 1998. Stress, culture and community: The psychology and philosophy of stress. New York: Plenum Press.

HOYT, M.F. 2000. Cognitive-behavioural treatment of post-traumatic stress disorder from a narrative constructivist perspective. A conversation with Donald Meichenbaum, D. In: SCOTT, M.J. \& PALMER, S (eds) Trauma and post-traumatic stress disorder. Wiltshire: Redwood Books.

JAMES, B. 1989. Treating traumatised children: New insights and creative interventions. Toronto: Lexington Books.

KISTNER, J. 2004. Grief and healing in the context of continuous trauma. SA Institute for Traumatic Stress. The Traumatic Stress Newsletter, 2:10-17.

McFARLANE, A.C. 1993. PTSD: Synthesis of research and clinical studies. The Australia Bushfire Disaster. In: WILSON, J.P. \& RAPHAEL, B. (eds) International handbook of traumatic stress syndromes. New York: Plenum Press: 421-429.

McKENDRICK, B.W. (ed) 1990. Social work in action. HAUM Tertiary: Pretoria.

MINISTRY OF WELFARE AND POPULATION DEVELOPMENT 1997. White Paper for Social Welfare. Pretoria, South Africa: Government Printer.

MONNIER, J. \& HOBFOLL, S.E. 2000. Conservation of resources in individual and community reactions to traumatic stress. In: SHALIEV, A.Y.; YEHUDA, R. \& MCFARLANE, A.C. 2000. International handbook of human response to trauma. New York: Kluwer Academic.

PALMARY, I. 2001. Social crime prevention in South Africa's major cities. Report prepared as part of the City Safety Project (funded by the Open Society Foundation for South Africa).

PEARLMAN, L.A. 2001. Treatment of persons with complex PTSD and other trauma-related disruptions of the self. In: WILSON, J.P.; FRIEDMAN, M.J. \& LINDY, J.D. 2001. Treating psychological trauma and PTSD. New York: Guilford Press.

PUTNAM, R.D. 2000. Bowling alone. The collapse and revival of American community. New York: Simon \& Schuster. 
SOUTH AFRICAN COMMUNICATIONS SERVICE. 1995. South African Yearbook. Pretoria: Government Printer.

SCHUMM, J.A.; HOBFOLL, S.E. \& KEOGH, N.J. 2004. Revictimization and interpersonal resource loss predicts PTSD among women in substance-use treatment. Journal of Traumatic Stress, 17(2):173-181.

VAN DER MERWE, M. 1999. A social work practice model for young children traumatised by witnessing sudden, unexpected extreme life events. Stellenbosch: University of Stellenbosch. (Unpublished DPhil Dissertation)

VAN DYK, A. 2001. HIV/AIDS care \& counselling. A multidisciplinary approach. Cape Town: Pearson Education.

Dr Mariette van der Merwe, Department of Social Work, Stellenbosch University, Stellenbosch; Dr Kailas Kassan-Newton, counselling psychologist in private practice, Cape Town, South Africa. 